\title{
Management of Idiopathic Intracranial Hypertension: Experience of a North African Center
}

\author{
Ibrahim Assoumane ${ }^{1,2}$ Mahdia Touati ${ }^{1}$ Harissou Adamou ${ }^{3}$ Nadia Lagha ${ }^{1} \quad$ Ibrahim Baaré \\ Samuila Sanoussi ${ }^{5} \quad$ Abderahmanne Sidi Said ${ }^{1} \quad$ Abdelhalim Morsli $^{1}$
}

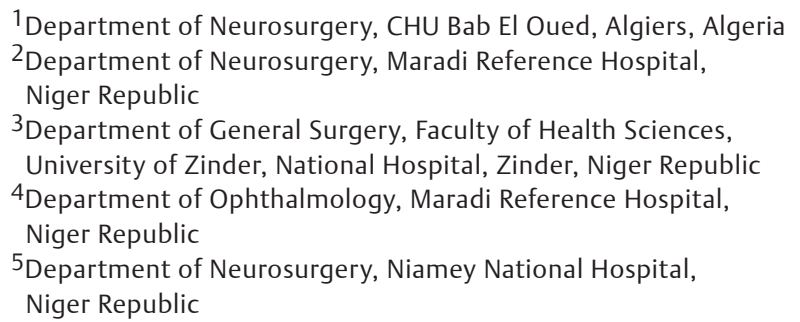

Address for correspondence Ibrahim Assoumane, MD, Maradi Reference Hospital, Niger Republic (e-mail: as_ibrah2006@yahoo.fr, assoubrahim18@gmail.com).

Indian J Neurosurg:2020;9:85-88

\begin{abstract}
Keywords

- idiopathic

- intracranial

hypertension

- lumbo-peritoneal

Background The idiopathic intracranial hypertension (IIH) is characterized by elevation of intracranial pressure (ICP) in the absence of intracerebral space occupation or venous sinus thrombosis. It usually occurs in obese young women but is very rare in childhood.

Materials and Methods We conducted a retrospective study in the neurosurgical department of Bab El Oued teaching hospital of Algiers over a period of 8 years from January 2008 to December 2015. We analyzed clinical data of 10 patients with IIH diagnosis, and the surgical technique consisted of an insertion of a lumbo-peritoneal shunt.

Results In our study, $80 \%$ were women with sex ratio M/F of 0.25 ; the mean age was 32 years and $60 \%$ of our patients were obese. For most of our patients, the postoperative outcome was marked by the disappearance of the headache immediately, disappearance of strabismus and diplopia in the following week, followed by improvement of visual function.

Conclusion The IIH is predominantly a disease of women in the childbearing age; surgical treatment is a good option for patients who resisted medication or did not tolerate it as well as for $\mathrm{ICH}$ fulminous in emergency cases.
\end{abstract}

\section{Introduction}

Idiopathic intracranial hypertension (IIH),was first described by Quincke in 1893 after the introduction of the lumbar puncture. ${ }^{1-5}$ It was also called pseudotumor cerebri by Nonne in 1904 or benign intracranial hypertension by Foley in $1955^{1,2,4}$ The first series was reported by Dandy in 1937., 2,6 The annual incidence of IIH is 1 to 3 per 100,000 in the general population. It is elevated to 20 per 10,000 among the female population of childbearing age. ${ }^{1,7}$ The etiology of IIH is not completely understood; however, female sex, obesity, endocrine disorders, and high-levels of vitamin A are risk factors incriminated. ${ }^{4,8}$ The IIH is characterized by elevation of intracranial pressure (ICP) in the absence of intracerebral space occupation or venous sinus thrombosis. IIH leads to permanent vision loss and refractory headaches that had failed medical management. ${ }^{1}$ It is a therapeutic emergency to preserve vision and reduce other symptoms. ${ }^{1,3,4}$ The aim of our study was to assess the clinical and therapeutic aspects of the idiopathic intracranial hypertension in our department.
DOI https://doi.org/

10.1055/s-0040-1710107

ISSN 2277-954X.
License terms

()(1) $\Theta \circledast$ 


\section{Materials and Methods}

We conducted a retrospective study in the neurosurgical department of Bab El Oued teaching hospital of Algiers over a period of 8 years from January 2008 to December 2015. We analyzed medical data of 10 patients presenting severe ocular signs associated to headaches not relieved by medical treatment and iterative lumbar punctures. The analysis included: the body mass index (BMI): below 18.5 = underweight, 18.5-24.9 = normal weight, above $25 \mathrm{Kg} / \mathrm{m}^{2}=$ obesity, neurologic examination, visual function tests, neuroimaging studies (brain computed tomography [CT] scan, brain magnetic resonance imaging [MRI]), cerebrospinal fluid (CSF) studies (cytology and biochemistry), ICP measurement, and treatment and outcome. The surgical technique consisted of an insertion of a lumbo-peritoneal shunt. Under general anesthesia and lateral position, the first step is a median skin incision from L3 to L5, and lumbar puncture at L4 L5 level to collect CSF for cytology follow by the intradural insertion of a $\mathrm{T}$ catheter at that level. The second step is a paraumbilical skin incision, exposition of the peritoneum, tunneling of the lumbar catheter to join the paraumbilical incision, verification of the leakage of CSF, and introduction of the catheter inside the peritoneum. The end of the procedure is the closure of the two incisions (lumbar and paraumbilical). The median follow-up is 12 months.

\section{Resuelts}

During our study, we registered 10 patients admitted for IIH. The mean age was 32 years (range: 9-48 years). There were eight women and two men with a sex ratio $\mathrm{M} / \mathrm{F}$ of 0.25 . Most of our patients were obese, $60 \%(n=6), 20 \%(n=2)$ are overweight, and only $20 \%(n=2)$ had normal weight. The most frequent clinical signs were headaches and decrease of visual acuity, representing $100 \%$ for each followed by transient visual obscurations, diplopia, and strabismus with 50, 30, and $10 \%$, respectively.

We summarize the socio-epidemiological, clinical, and paraclinical characteristics and outcomes of patients in - Table 1.

The fundus examination objectified bilateral papillaroedema in $80 \%$, while bilateral optic atrophy was present in $20 \%$. Visual field was constricted in seven cases which represent $70 \%$ but normal in just one case; the test was impossible in two cases ( - Fig. $\mathbf{1}$ ).

We performed brain MRI for all our patients: this investigation objectified empty sella in five patients (50\%), tortuosity of the optic nerve in six patients (60\%), protrusion of optic nerve papillae into vitreous in all the patients (100\%), and flattening of the posterior sclera in two patients (20\%) ( - Fig. 2).

We operated 10 patients under general anesthesia on lateral position and performed the insertion of a lumboperitoneal shunt for all of them. The postoperative outcome was good for the majority of patients $(8=80 \%)$ because all of them experienced disappearance of the headache immediately, and disappearance of strabismus and diplopia in the following week. The visual function improved for eight cases representing $80 \%$, but there was bilateral optic atrophy, leading to blindness in two cases (20\%). We noticed postoperative complications obstructing the peritoneal catheter (two cases), which represented $20 \%$ of our series at 12 months postoperation and the migration of the catheter in one case $(10 \%) 3$ weeks after surgery. We managed the complications by revising the shunt in two cases of obstruction and changed the whole shunt in the case of the intra-abdominal migration.

\section{Discussion}

The incidence of IIH is approximately 1 to 3 per 100,000 in the general population., ${ }^{4,-11}$ The most reported risk factors are female sex and obesity. In our study, there were eight women and two men with a sex ratio $\mathrm{M} / \mathrm{F}$ of 0.25 , mean age of 32 years, and obesity representing 60\%. Many authors reported especially high rates among young women suffering from obesity ${ }^{11,12}$; Ali et $\mathrm{al}^{8}$ reported childbearing age in $99 \%$. For Grant et $\mathrm{al}^{9}{ }^{9}$ there is no incidence of sex in a review of 79 cases in infancy and childhood. In our study, the most frequent clinical signs are headaches and decrease of visual acuity, as reported by many authors. ${ }^{14,12,13}$ The main neuroimaging findings that may accompany IIH are empty sella (70\%), distension (45\%), and tortuosity $(40 \%)$ of the perioptic subarachnoid space, flattening of the posterior sclera (80\%), and protrusion of optic nerve papillae into the vitreous and transverse sinus stenosis (90\%)., ${ }^{5,14,15}$

IIH corresponds an increased ICP of unknown cause (thereby excluding secondary intracranial hypertension)., ${ }^{4,7}$

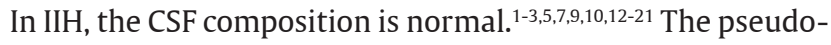
tumor name cerebri seems incorrectly understood, since it includes secondary causes of intracranial hypertension with the exception of lesions occupying space. ${ }^{3,4}$ It is more logical to call them pseudotumor cerebri primitive. ${ }^{4}$

Despite the number of pathogenesis theories that have been proposed, the cause of IIH is still unknown. Basic mechanisms that could explain a sustained intracranial hypertensive state in otherwise healthy subjects include: (1) increased CSF production rate, (2) cerebral edema, and (3) reduced CSF absorption. ${ }^{5,10}$ IIH is believed to result from irregularities of CSF production, distribution, and absorption; however, etiopathogenesis still remains unclear.,10,21

Diagnostic criteria for IIH was developed in 1937 by Dandy and modified in 2002 by Friedman and Jacobson ${ }^{22}$ who defined the disorder according to the following characteristics:

- Symptoms related to increased ICP with unknown etiology and no neurologic signs of focalization.

- Normal brain imaging.

- Elevated CSF pressure: > $20 \mathrm{~mm} \mathrm{Hg}$ for nonobese patients and $25 \mathrm{~mm} \mathrm{Hg}$ for obese patients.

- Normal composition of the CSF.

- No other etiology of ICH. ${ }^{1,13,15,21}$

The advance of imaging has significantly modified the evaluation of patients with possible IIH. ${ }^{13}$ 
Table 1 The socio-epidemiological, clinical, paraclinical characteristics and outcomes of patients

\begin{tabular}{|c|c|c|c|c|c|c|c|}
\hline No. & Age (y) & Sex & BMI & Clinical signs & Results of MRI & Complications & LOS \\
\hline 1 & 48 & $\mathrm{~F}$ & 22.5 & $\begin{array}{l}\text { Headaches } \\
\text { Decrease of VA } \\
\text { TVO }\end{array}$ & $\begin{array}{l}\text { Empty sella } \\
\text { Tortusity ON } \\
\text { Protrusion ON }\end{array}$ & $\begin{array}{l}\text { Obstruction of the } \\
\text { abdominal catheter }\end{array}$ & 10 \\
\hline 2 & 32 & $\mathrm{~F}$ & 28.3 & $\begin{array}{l}\text { Headaches } \\
\text { Decrease of VA } \\
\text { TVO }\end{array}$ & $\begin{array}{l}\text { Tortusity ON } \\
\text { Protrusion ON } \\
\text { FPS }\end{array}$ & None & 10 \\
\hline 3 & 9 & $\mathrm{~F}$ & 31.4 & $\begin{array}{l}\text { Headaches } \\
\text { Decrease of VA } \\
\text { Diplopia }\end{array}$ & $\begin{array}{l}\text { Empty sella } \\
\text { Protrusion ON }\end{array}$ & None & 8 \\
\hline 4 & 15 & $\mathrm{~F}$ & 32.7 & $\begin{array}{l}\text { Headaches } \\
\text { Decrease of VA } \\
\text { Diplopia }\end{array}$ & $\begin{array}{l}\text { Empty sella } \\
\text { Protrusion ON }\end{array}$ & None & 10 \\
\hline 5 & 26 & $\mathrm{M}$ & 27.8 & $\begin{array}{l}\text { Headaches } \\
\text { Decrease of VA } \\
\text { Strabismus }\end{array}$ & $\begin{array}{l}\text { Tortusity ON } \\
\text { Protrusion ON } \\
\text { FPS }\end{array}$ & None & 10 \\
\hline 6 & 30 & $\mathrm{~F}$ & 39.4 & $\begin{array}{l}\text { Headaches } \\
\text { Decrease of VA } \\
\text { TVO }\end{array}$ & $\begin{array}{l}\text { Empty sella } \\
\text { Protrusion ON }\end{array}$ & $\begin{array}{l}\text { Migration of the catheter } \\
\text { in the abdomen }\end{array}$ & 10 \\
\hline 7 & 34 & $\mathrm{~F}$ & 35.8 & $\begin{array}{l}\text { Headaches } \\
\text { Decrease of VA } \\
\text { TVO }\end{array}$ & $\begin{array}{l}\text { Tortusity ON } \\
\text { Protrusion ON }\end{array}$ & $\begin{array}{l}\text { Obstruction of the } \\
\text { abdominal catheter }\end{array}$ & 10 \\
\hline 8 & 38 & $\mathrm{M}$ & 38.6 & $\begin{array}{l}\text { Headaches } \\
\text { Decrease of VA }\end{array}$ & $\begin{array}{l}\text { Tortusity ON } \\
\text { Protrusion ON }\end{array}$ & None & 10 \\
\hline 9 & 40 & $\mathrm{~F}$ & 23.1 & $\begin{array}{l}\text { Headaches } \\
\text { Decrease of VA } \\
\text { TVO }\end{array}$ & $\begin{array}{l}\text { Tortusity ON } \\
\text { Protrusion ON }\end{array}$ & None & 10 \\
\hline 10 & 28 & $\mathrm{~F}$ & 37.7 & $\begin{array}{l}\text { Headaches } \\
\text { Decrease of VA } \\
\text { Diplopia }\end{array}$ & $\begin{array}{l}\text { Empty sella } \\
\text { Protrusion ON }\end{array}$ & None & 10 \\
\hline
\end{tabular}

Abbreviations: FPS, flattening of the posterior sclera; LOS, length of stay (days); N, normal weight; OB, obese; ON, optic nerve; OV, overweight; TVO, transient visual obscuration; VA, visual acuity.

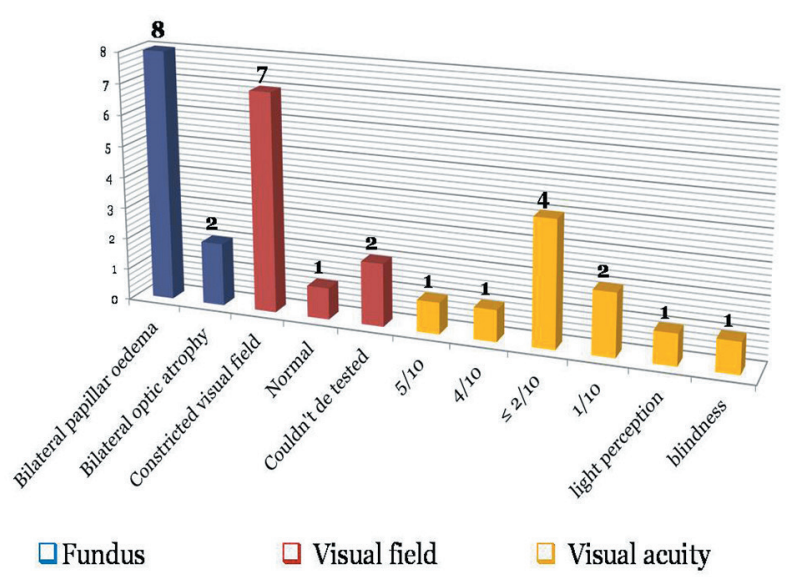

Fig. 1 Repartition of the patients by visual function test resukts.

The main goal of the treatment was to reduce ICP in order to avoid blindness by papillary edema in emergency. There exist many options for the treatment of IIH even if there are no precise guidelines for that nowadays. IIH does not currently have a well-established management algorithm, given the paucity of studies on the issue. . $^{1,3,8,17,19}$ Kalyvas et $\mathrm{al}^{15}$ in a systemic review of literature declare that treatment options range from conservative to interventional and surgical.
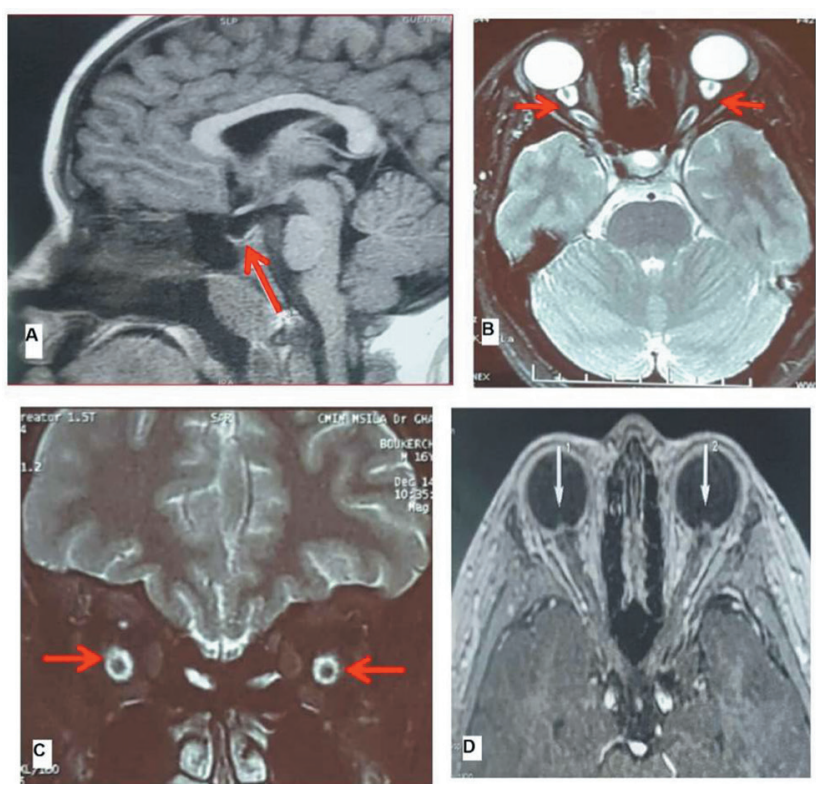

Fig. 2 (A) Empty sella (red arrow). (B) Optic nerve tortuosity (red arrow). (C) Distension of perioptic subarachnoid space. (D) Protrusion of optic nerve papillae into vitreous (arrow).

Conservative options include weight loss, drugs (acetazolamide, topiramate, furosemide, or octreotide), and serial lumbar punctures. Interventional and surgical options are 
CSF diversion procedures (ventriculo-peritoneal or lumboperitoneal shunting), optic nerve sheath fenestration (ONSF), venous sinus stenting, and bariatric surgery. ${ }^{15}$ Headache disappears immediately after the lumbo-peritoneal shunt insertion for all our patients, but there was bilateral optic atrophy leading to blindness in two cases (20\%). Moataz et al ${ }^{19}$ reported the improvement of headaches in 10 patients (45.5\%) with complete resolution of papillar edema, gradually in $100 \%$ after 4 weeks. The most frequent complication in our series is the obstruction of the peritoneal catheter in $20 \%$ of our series followed by the migration of the catheter in the abdomen in $10 \%$. Being an extra-cranial procedure, lumbo-peritoneal shunt insertion has a lower complication rate. Shunt obstruction and infections are the most common complications of this operation. ${ }^{18}$

\section{Conclusion}

IIH is characterized by elevated CSF pressure of unknown cause; it is predominantly a disease of women belonging to the childbearing age. It became clear that loss of visual function is common and patients might progress to blindness if untreated. Surgical treatment is allowed for patients who resisted medication or did not tolerate it as well as for $\mathrm{ICH}$ fulminous in emergency cases.

\section{Conflict of Interest}

None declared.

\section{References}

1 Bjornson A, Tapply I, Nabbanja E, et al. Ventriculo-peritoneal shunting is a safe and effective treatment for idiopathic intracranial hypertension. Br J Neurosurg 2019;33(1):62-70

2 Karsy M, Abou-Al-Shaar H, Bowers CA, SchmidtRH. Treatment of idiopathic intracranial hypertension via stereotactic placement of biventriculoperitoneal shunts. J Neurosurg 2018;130(1): 136-144

3 Baykan B, Ekizoğlu E, Altıokka Uzun G. An update on the pathophysiology of idiopathic intracranial hypertension alias pseudotumor cerebri. Agri 2015;27(2):63-72

4 Akçakaya NH, Akçakaya MO, Sencer A, Yapici Z. Idiopathic intracranial hypertension: diagnosis and therapeutic approach. Turk J Neurol 2017;23(2):43-50

5 De Simone R, Ranieri A, Bonavita V. Advancement in idiopathic intracranial hypertension pathogenesis: focus on sinus venous stenosis. Neurol Sci 2010;31(1, Suppl 1):S33-S39
6 Spitze A, Malik A, Lee AG. Surgical and endovascular interventions in idiopathic intracranial hypertension. Curr Opin Neurol 2014;27(1):69-74

7 Smith SV, Friedman DI. The idiopathic intracranial hypertension treatment trial: a review of the outcomes. Headache 2017;57(8):1303-1310

8 Ali AK, Shousha MM, Metwally MR. Management of pseudo tumor cerebri by frequent tapping vs lumboperitoneal shunt. Egypt J Hosp Med 2018;72(5):4556-4560

9 Grant DN. Benign intracranial hypertension. A review of 79 cases in infancy and childhood. Arch Dis Child 1971;46(249): 651-655

10 De Simone R, Ranieri A, Montella S, Friedman DI, Liu GT, Digre KB. Revised diagnostic criteria for the pseudotumor cerebri syndrome in adults and children. Neurology 2014;82(11): 1011-1012

11 Barmherzig R, Szperka CL. Pseudotumor cerebri syndrome in children. Curr Pain Headache Rep 2019;23(8):58

12 Skau M, Brennum J, Gjerris F, Jensen R. What is new about idiopathic intracranial hypertension? An updated review of mechanism and treatment. Cephalalgia 2006;26(4):384-399

13 Rehder D. Idiopathic intracranial hypertension: review of clinical syndrome, imaging findings, and treatment. Curr Probl Diagn Radiol 2019;:S0363-0188(18)30257-3

14 Riggeal BD, Bruce BB, Saindane AM, et al. Clinical course of idiopathic intracranial hypertension with transverse sinus stenosis. Neurology 2013;80(3):289-295

15 Kalyvas AV, Hughes M, Koutsarnakis C, et al. Efficacy, complications and cost of surgical interventions for idiopathic intracranial hypertension: a systematic review of the literature. Acta Neurochir (Wien) 2017;159(1):33-49

16 Burgett RA, Purvin VA, Kawasaki A. Lumboperitoneal shunting for pseudotumor cerebri. Neurology 1997;49(3):734-739

17 Eggenberger ER, Miller NR, Vitale S. Lumboperitoneal shunt for the treatment of pseudotumor cerebri. Neurology 1996;46(6):1524-1530

18 Gupta B, Panigrahi M. Acquired Chiari I malformation following a lumbo-peritoneal shunt-William's hypothesis revisited. J Med Sci Res 2013;1(1):13-15

19 Moataz AE, Elmaghrabi MM. Neurological and ophthalmological recovery after lumbo-peritoneal shunting as a treatment of idiopathic intracranial hypertension. Int J Adv Res (Indore) 2017;5(9):914-920

20 Sinclair AJ, Kuruvath S, Sen D, Nightingale PG, Burdon MA, Flint $G$. Is cerebrospinal fluid shunting in idiopathic intracranial hypertension worthwhile? A 10-year review. Cephalalgia 2011;31(16):1627-1633

21 Wakerley BR, Tan MH, Ting EY. Idiopathic intracranial hypertension. Cephalalgia 2015;35(3):248-261

22 Friedman DI, Jacobson DM. Diagnostic criteria for idiopathic intracranial hypertension. Neurology 2002;59(10):1492-1495 